\title{
Afinal, livro por quê?
}

\section{After all, why books?}

LETÍCIA LAMPERT

Pesquisadora independente

\section{RESUMO}

Este artigo traz uma reflexão sobre as razões que levam artistas a optar pelo livro como forma de realizar seus projetos, considerando vantagens e desvantagens do formato, além de questões conceituais e pragmáticas que podem estar diretamente relacionadas a este processo. Partindo da experiência pessoal da autora em diferentes publicações, serão abordados processos e motivações por trás de projetos como Escala de Cor do Tempo, Escala de Cor das Coisas, Entre, Manual Prático de Arquitetura, 拆 [chai] e Conhecidos de Vista.

\section{PALAVRAS-CHAVE}

Livro de artista, fotolivro, processo criativo, fotografia, arte

\begin{abstract}
A B S T R ACT
This paper reflects on the reasons that lead artists to choose the book as a way to produce their projects, considering the advantages and disadvantages of the format, besides conceptual and pragmatic issues that may be directly related to the process. Based on the author's personal experience in different publications, it will be addressed processes and motivations behind projects such as The Color Scale of Things, The Color Scale of Time, Entre, Manual Prático de Arquitetura, 拆 [chai] and Known by Sight.
\end{abstract}

\section{KEYWORDS}

Artist's book, photobook, creative process, photography, art 
Para John Baldessari, uma forma de manter a arte acessível a todos. Para Lucy Lippard, um meio de ter voz e contornar o machismo das instituições. Para Sol LeWitt, uma maneira de levar ideias e ser melhor compreendido por um maior número de pessoas. Muitas são as razões que fazem artistas buscar no livro a forma de concretizar seus projetos. E isto não é de hoje. Estas e muitas outras respostas estão reunidas na edição número 14 da revista Art-Rite, publica em 1976, sobre o porquê de se sentirem atraídos por livros de artistas e quais os maiores potenciais e dificuldades deste tipo de arte. Democratizar o acesso e descentralizar o poder estavam entre as questões mais recorrentes.

Quase 50 anos depois, livros de artista seguem mobilizando um circuito de entusiastas e suscitando curiosidade e estranhamento na grande maioria do público leigo. Embora o campo tenha se ampliado bastante, movimentando toda uma rede de artistas, editoras e feiras, as possibilidades e contradições que permeiam este universo parecem ter mudado muito pouco de lá pra cá.

Talvez o que mais tenha mudado seja um certo idealismo perdido, tão característico dos anos 60 e 70, expresso na vontade de romper com o status quo e na radicalidade de ideias e atitudes que foram sendo, como sempre, absorvidas pelo próprio sistema que pretendiam criticar. Vejo hoje, com certo espanto, uma significativa parcela de artistas e curadores entenderem, ou mesmo defenderem, que para um livro ser "de artista" ele deve ter tiragens limitadas, assinadas, acabamentos especiais, estas coisas que o diferenciariam de um objeto industrializado, como se assim fosse perder a tal aura da obra única e feita à mão, colocada já em cheque no início do século passado por figuras como Duchamp, na prática, e Walter Benjamin, na teoria. O que será que Sol LeWitt e Lucy Lippard (e tantos outros!) diriam de tamanha distorção das motivações por trás daquela cena que efervescia nos anos 70, a ponto de se reunirem para criar um espaço como o Printed Matter, em Nova York, dedicado inteiramente à produção e circulação de livros de artistas com o objetivo de ser o mais democrático possível?

Lucy Lippard é bastante categórica em sua definição:

Livro de artista significa um livro feito por um artista. (...) Minha própria definição de livro de artista é bem estrita: produto de massa, relativamente barato, acessível a um público amplo, todo arte e sem comentário ou prefácio ou qualquer coisa escrita por artista ou crítico que não seja parte do trabalho; a natureza sequencial faz dele uma peça em si (talvez às vezes uma "exposição" inteira, mas isto nunca me interessou tanto quanto a visão holística de determinada obra). Livros únicos e feitos à mão eram outra coisa - geralmente muito bonitos, mas o tipo de "objeto precioso" que eu esperava que conseguíssemos escapar. (LIPPARD, 2006) (tradução nossa) ${ }^{1}$

1 No original: Artist's book meant a book by an artist. (..) My own definition of an artist's book was quite strict: mass produced, relatively cheap, accessible to a broad public, all art and no commentary or preface or anything that wasn't part of the artwork by anyone-artist or critic; the sequential nature made it a single piece (maybe at times a whole "exhibition" but that never appealed to me as much as the holistic view). Handmade, one-of-a-kind books were something else-often very beautiful, but the kind of "precious objects" I hoped we'd escape. (LIPPARD, 2006) 
Produzir largas tiragens, usar materiais baratos, estar em todos lugares, nas livrarias, nas lojas, se possível até nos supermercados, era isto que eles buscavam e é onde sigo entendendo a maior potência deste tipo de trabalho. Furar a bolha da arte elitista, conquistar novos públicos. Mas ser acessível em termos de forma e preço, não garante ser acessível em outros âmbitos. A própria Lucy Lippard alerta para uma contradição que vinha junto com esta visão bem dogmática, ainda que se pretendesse libertária, que tinha dos livros de artista: a dificuldade de o público leigo entender e se interessar por aquelas publicações. Mesmo que a intenção fosse popularizar a arte através de objetos baratos que circulassem fora do cubo branco, formatos estranhos e narrativas muito herméticas faziam com que o público interessando se resumisse a colecionadores e iniciados no assunto. Se mesmo entre artistas é ainda hoje comum encontrar discordâncias sobre o que define este tipo de obra, o que dirá entre leigos, este grande público em potencial que tanto queremos alcançar, que muitas vezes nunca nem ouviu falar que um livro pode ser entendido como uma obra de arte tanto quanto um quadro na parede, uma instalação ou uma escultura são de maneira mais óbvia?

Acho interessante quando ela menciona a questão da total eliminação de qualquer texto crítico ou de apresentação, para não quebrar este caráter de obra que este tipo de livro quer assumir. De fato, via de regra, quando se trata de desenho, escultura, ou seja lá o que for, a obra não vem com uma bula ou manual de instruções. O próprio estranhamento pode ser parte importante do processo de aproximação. Mas, normalmente, este tipo de obra também não é distribuído em lojas ou livrarias comuns, se entrelaçando com um outro campo de conhecimento, a literatura, e carregando consigo o intuito de furar a bolha de um circuito especializado para alcançar o espectador mais desavisado. Vi esta discussão voltar com força junto com a efervescência mais recente dos fotolivros, este outro movimento, muito similar e às vezes indistinguível ao dos livros de artistas, mas que pode também carregar suas nuances próprias sendo a fotografia um campo tão diverso quanto é.

Pessoalmente, embora entenda a relutância dos mais puristas em relação à inserção de textos nos livros de artista e fotolivros, acredito que, se queremos alcançar um público que ainda não está devidamente familiarizado com este tipo de obra, talvez seja preciso dar a mão, talvez seja preciso criar artifícios e romper com uma certa soberba que espera entendimento e interesse automáticos. A dificuldade e o estranhamento já vêm de um formato inesperado de arte, já vem de estar em um ambiente inesperado para encontrar arte, e ainda pode ser acentuado pela natureza de um conteúdo muito hermético ou autocentrado. Não é questão de subestimar o público ou depreciar a autonomia da obra, mas de ser generoso (e talvez estratégico) o suficiente para oferecer uma chave de leitura quando esta se mostrar necessária. Digo isto por que é sempre importante analisar cada projeto e cada contexto em suas particularidades para chegar ao melhor juízo, não acredito em regras que se apliquem a tudo, especialmente quando estamos no campo da arte.

Mas se existe esta postura política de romper com o sistema e de furar a bolha de um circuito muito elitista e fechado, há também outros fatores que podem levar os artistas a flertar com o universo editorial. Afinal, o livro, como objeto, não é nada neutro. Ele vem carregado de significados, evocações culturais, características formais que podem ser a razão de um projeto 
virar livro. Desde o tipo de papel, a encadernação, o material, até mesmo o preço, tudo pode contribuir, quando elaborado com intenção, para dar sentido a um trabalho. Livro é forma, e forma é conteúdo. Livro é lugar, estende o tempo e cria espaço. É um aqui e agora, no ritmo estabelecido pelo leitor. É um lugar de intimidade, uma conversa a dois. É portátil e versátil, pode tanto caber no bolso - como um objeto banal para ser folheado a qualquer hora, quanto ter algo de precioso e raro - exigindo até luvas para ser manuseado. 0 livro traz com ele a serialidade, a tiragem, a circulação, a possibilidade de comercialização, a permanência. Traz a relação com a biblioteca, com a enciclopédia, com o saber. Livro evoca literatura, narratividade, conhecimento e também legitimação. Livro é sempre um pouco de tudo isto ao mesmo tempo, embora possa carregar pesos maiores em determinadas características conforme as intenções de cada projeto.

\section{Questão de conceito}

Se o mais corriqueiro é entender o livro como a consolidação de um projeto acabado, como o ponto final de uma longa jornada, quando o livro é proposto como obra esta relação pode ser completamente invertida. Há muitos casos onde o formato livro é o próprio ponto de partida, o norte que aponta para a sua melhor forma de existir, a razão de ser de um projeto elaborado para este fim. Dentro da minha produção pessoal, as "Escalas de Cor", "do Tempo" e "das Coisas" (Figuras 1 e 2), exemplificam bem este processo.

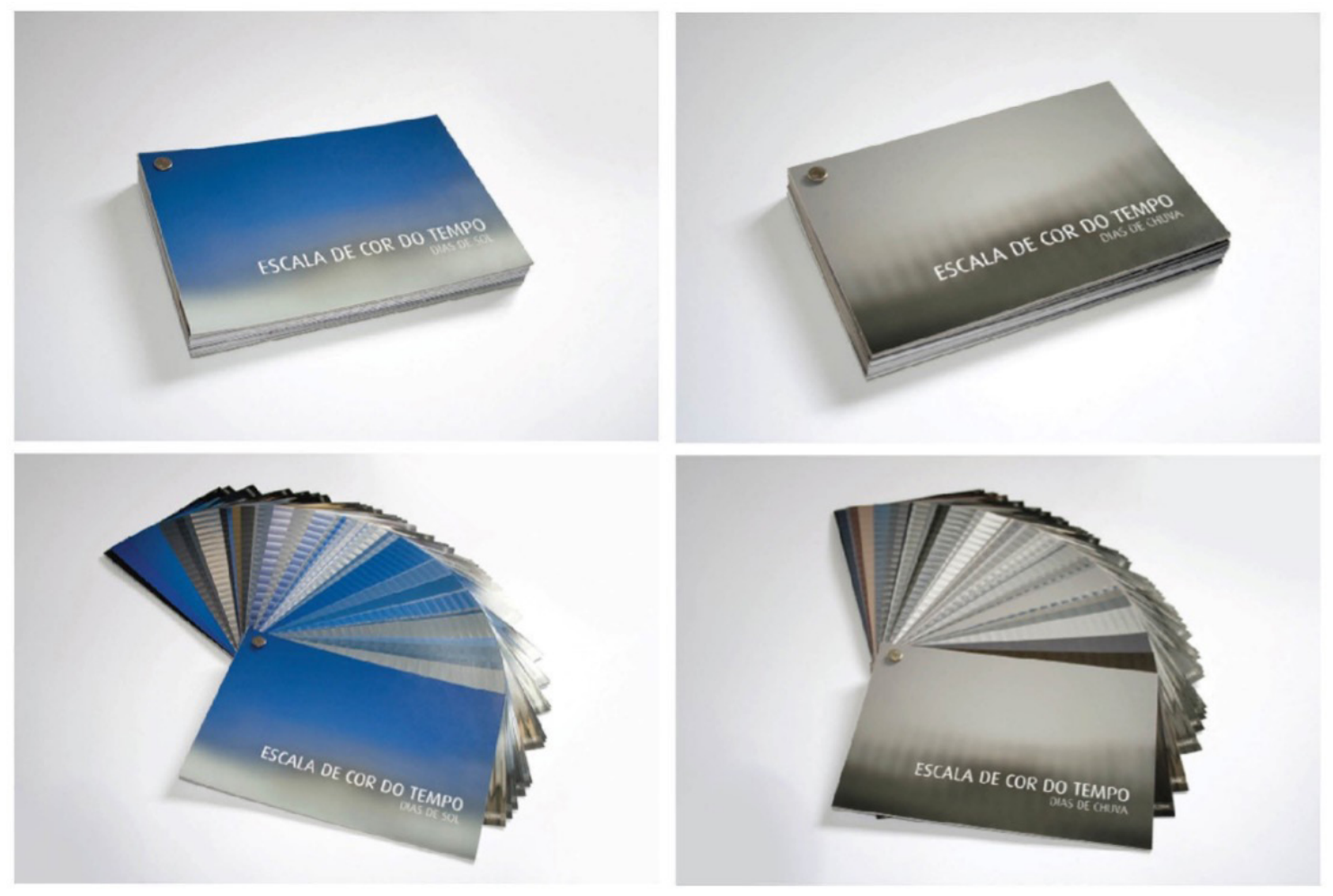

Figura 1. Escala de Cor do Tempo - Para dias de Sol e Para dias de Chuva, 2009. Impressão digital, $10 \times 15 \times 1 \mathrm{~cm}$, edição por demanda. Fonte do autor 


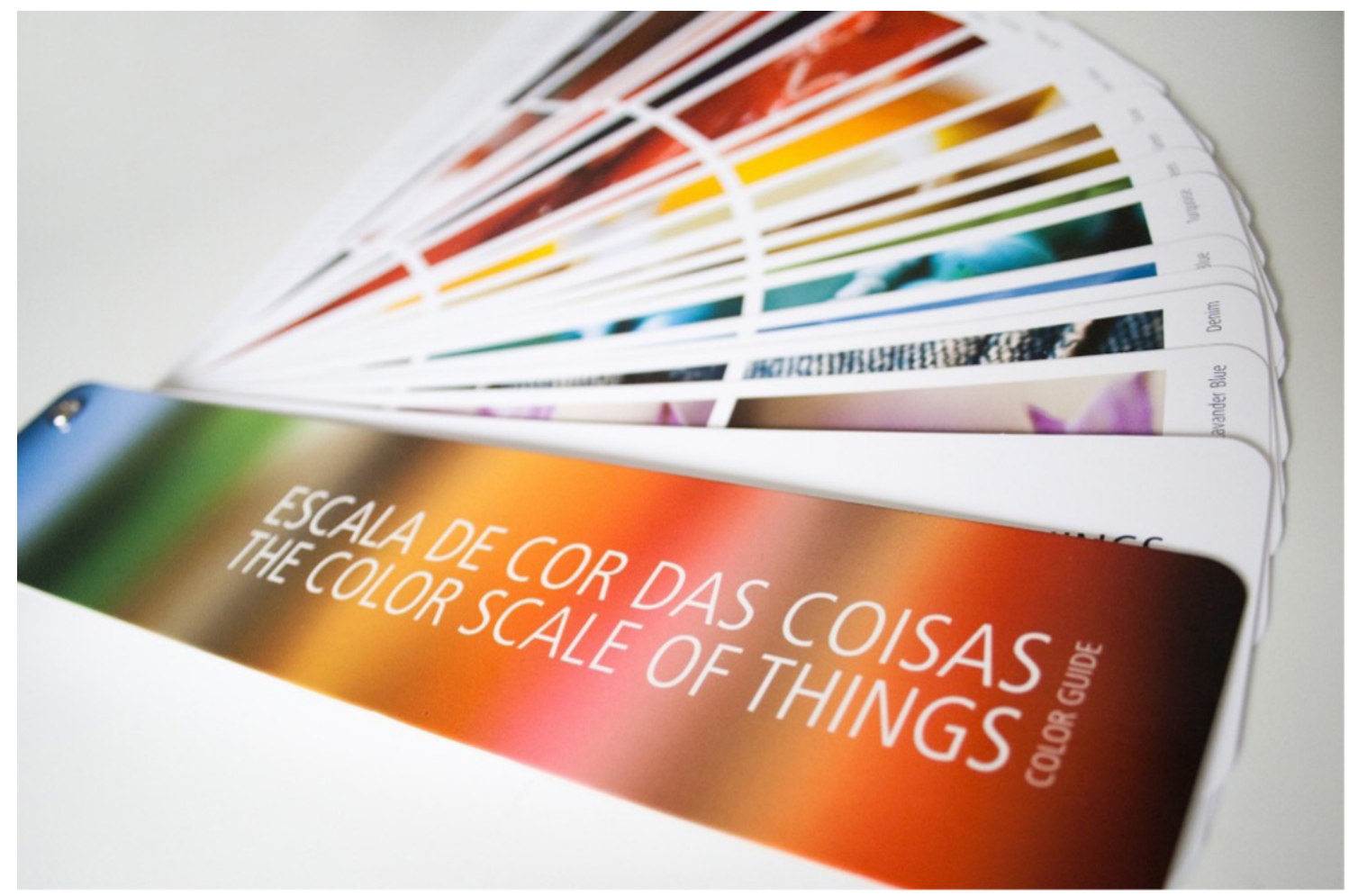

Figura 2. Escala de Cor das Coisas, 2009. Impressão offset, $6 \times 28 \times 2 \mathrm{~cm}$, edição de 1500 exemplares. Fonte do autor

A "Escala de Cor do Tempo" foi o resultado do ato sistemático de fotografar a janela basculante do banheiro do apartamento onde morava para captar a variação de cores que se formavam no vidro canelado. A associação que eu fazia, e que me movia a seguir colecionando as diferentes tonalidades que mudavam conforme as horas, eram as paletas de tintas. Se com tintas acrescenta-se determinado pigmento pra chegar de um tom a outro, na minha escala era adicionado tempo. Logo, foi se formando um grid que mais parecia uma cartela CMYK, destas que são distribuídas pelas gráficas como referência para garantir precisão na hora de reproduzir as cores. Ou então, quando empilhava as fotografias que ia imprimindo no formato $10 \times 15 \mathrm{~cm}$ para poder editar, parecia que tinha um mostruário de cores em mãos, destes em forma de leque que são usados para uma variedade de materiais, como tintas, acabamentos e tecidos. Foi assim que este formato acabou sendo incorporado e definindo a forma de existir do projeto.

Na mesma época, e em decorrência deste processo de aproximação com catálogos e mostruários, passei a prestar a atenção nos nomes que são dados às cores. Pensava com curiosidade nos nomes de determinadas tintas, esmaltes de unha, ou mesmo nas palavras que usamos na linguagem corriqueira para tentar decodificar um tom que queremos descrever. Muitas vezes eram coisas palpáveis, coisas que poderiam ser fotografadas por mim numa tentativa de tradução literal e visual da palavra. Azul-calcinha, verde-folha, amarelo ovo, foram algumas das cores que foram compondo a "Escala de Cor das Coisas". Desta vez, pelo leque maior de tonalidades, a associação 
com o "Pantone", este sistema amplamente utilizado no mundo todo para normatizar a impressão de cores, foi bastante natural. Era este o formato que o projeto deveria ter, foi a partir dele que fui montando minha paleta.

Mas para me apropriar verdadeiramente desse formato, para fazer uma citação mais contundente a este sistema tão conhecido, eu não podia ficar apenas na forma. 0 tipo de impressão, o tipo de papel, o acabamento, a comercialização em livrarias, tudo ajudava a dar sentido ao trabalho. Era um projeto que precisava ser produzido em offset, precisava de papel couchê, precisava estar à venda em livrarias junto aos livros "sérios" e profissionais de cor que existem no mercado para assim ter seu sentido poético realizado com maior potência. É um projeto que precisava ser livro para existir. E assim foi. Produzida pela primeira vez em 2009 com financiamento do Fumproarte e tiragem de 1000 exemplares, a “Escala de Cor das Coisas" esgotou em 2013. Em 2014, decidi produzir uma nova tiragem, desta vez de 1500 exemplares e viabilizada através de financiamento coletivo pelo site Catarse. A experiência do financiamento coletivo, embora extremamente trabalhosa e extenuante, se mostrou bastante eficiente não apenas por viabilizar a continuação do projeto, mas também por garantir uma ampla distribuição já de saída. A distribuição é sempre um gargalo importante a ser considerado e um fator determinante a se pensar no momento de decidir a tiragem de um projeto.

\section{O fazer pelo fazer ou a página imprensa como espaço de experimentação}

Publicar um projeto traz um certo glamour que nem sempre o livro, como um trabalho de artista, deveria ter. No senso comum, publicar um livro é uma consagração. Talvez o mesmo constrangimento que a palavra artista causa, quando empregada como adjetivo. Fulano pode ser um "artista” em alguma coisa por ser muito bom naquilo faz. Mas pode ser simplesmente um artista por que a arte é seu ofício, faça ele bem ou mal o seu labor. Há que se desglamourizar a palavra para entender o fazer do artista. Há que se desglamourizar o livro para entender ele como mais um formato possível para fazer arte.

Nesta linha de pensamento, um livro pode ser só mais um trabalho, a materialização de uma ideia, uma forma de existir, mesmo que isto não esteja relacionado com o conceito em si do projeto, como no caso anterior. A página impressa pode ser simplesmente o laboratório para botar as ideias em prática, um espaço de experimentação que abre possibilidades poéticas. Como um pintor que pinta um, dois, dez quadros, o artista-editor pode produzir um, dois, dez livros. Talvez um ou outro terão mais envergadura e serão dignos de investimentos em tiragens maiores e todo trabalho de distribuição e comercialização que vem com elas, enquanto outros serão importantes apenas para o desenvolvimento do seu processo criativo e poética pessoal. E isto, do ponto de vista do seu aprimoramento como artista, não é menos relevante. O fotógrafo americano Alec Soth, quando questionado sobre o seu processo de produção e suas intenções ao fazer um livro, faz uma relação bem interessante com o processo de trabalho dos músicos:

Minha intenção é fazer um grande livro. Isto é o que quero fazer. E o que isso significa? Não tenho ideia do que é um grande livro. O que eu sei é que não existe fórmula. É como um grande álbum, talvez a banda tenha passado 3 anos no estúdio 
gravando, ou talvez tenha sido uma gravação em tomada única, ao vivo, durante um fim de semana. Sabendo que não existe fórmula, eu sei que preciso continuar me movimentando, então faço algo rápido, depois faço algo que leva anos, tentando coisas diferentes. Faço coisas onde trabalho sozinho, faço coisas de forma colaborativa. Às vezes não dá em nada mas, com sorte, a mágica acontece em algum momento. (SOTH, s.d.) (tradução nossa) ${ }^{2}$

Soth enfatiza a importância de seguir em movimento, de seguir fazendo para poder se aprimorar. José Diniz, artista e fotógrafo carioca, também trabalha muito dentro desta lógica. Em live $^{3}$ recente organizada pela Fotô Editorial, ele comentou que pensa seus projetos através dos livros artesanais que vai criando. Alguns viram bonecos para livros futuros em maior tiragem, outros se encerram neste próprio processo artesanal. Mas a questão principal é que organizar suas imagens na forma de livro é parte indissociável do seu processo criativo.

Em 2008, quando fiz minha primeira exposição individual, “(des)construções”, me coloquei o desafio de transpor aquela série para o formato livro. Na verdade, era um desafio a longo prazo: estabeleci que sempre que fizesse uma série, faria também o livro do projeto. Uma proposta que me estimulava como artista e me desafiava como designer, aproveitando que, de fato, transito profissionalmente entre os dois campos. Uma proposta que não cheguei a seguir à risca, mas que me ajudou a colocar vários trabalhos e ideias em movimento.

Fato é que o simples exercício de transpor um trabalho para a página impressa traz novas possibilidades e entendimentos sobre ele. 0 projeto em questão era uma série de colagens onde misturava diferentes partes de prédios da Porto Alegre criando novas e improváveis moradias. Para mim, as fotografias que usava eram como palavras que precisavam ser reunidas para ter sentido. Também como palavras, acaba repetindo algumas delas em diferentes composições. Esta repetição me levou a pensar numa solução onde a junção pudesse acontecer através das páginas, com recortes que permitiriam a imagem se completar na página seguinte, revelando assim o processo criativo por trás do trabalho. A relação criada neste jogo era na verdade muito mais potente que na própria exposição. Mas para isto acontecer, não bastava simplesmente sequenciar as imagens, era necessário refazer algumas colagens e substituir partes para conseguir encaixar da forma cadenciada que eu queria. No fim, o próprio trabalho foi se modificando para funcionar na sequência do livro, que se chamou "Entre" (Figura 3). Alguns anos depois, fiz outro trabalho seguindo esta mesma lógica de colagem e recorte, o "Manual Prático de Arquitetura” (Figura 4).

2 No original: My aim is to try to make a great book. That's what I want to do. And what does that mean? I have no idea what a great book is. What I do know is that it isn't a formula. It's like a great album, maybe the band has to spend three years in the studio doing it or maybe it's live in one take over a weekend. Knowing it's not a formula, I know that I have to keep shaking these up, so I do something fast, then do something that takes years, trying different things. Do the stuff where I work alone, do the stuff where I work collaboratively. Sometimes it will fall flat, but hopefully magic will strike at some point. (SOTH, s.d.)

3 Live realizada no canal de Instagram @ateliefotoeditorial, no dia 1 de agosto de 2020, às 11h, na qual participei como convidada. 


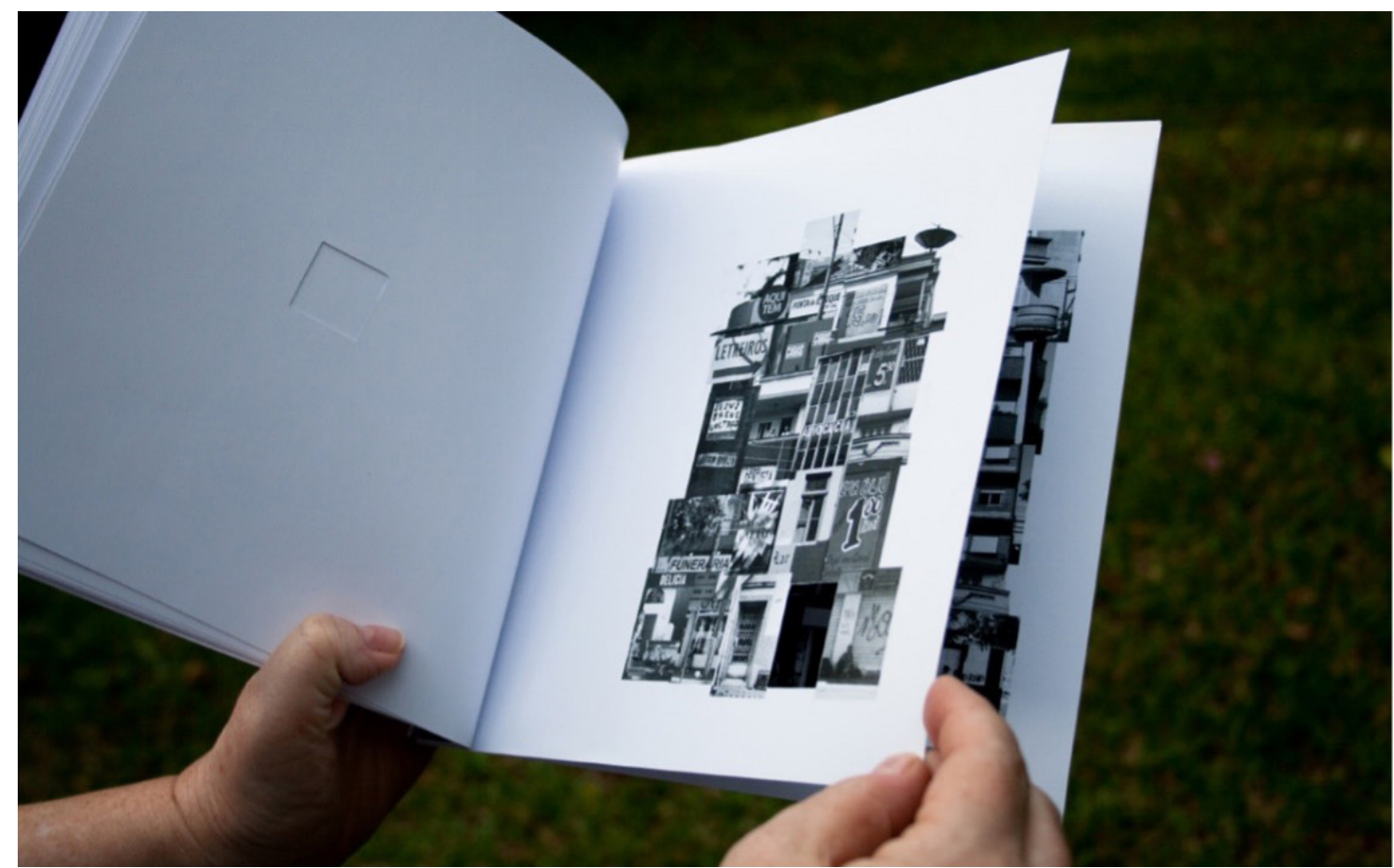

Figura 3. Entre, 2008. Primeira edição. Impressão digital, $20 \times 20 \times 1 \mathrm{~cm}$, edição por demanda. Fonte do autor

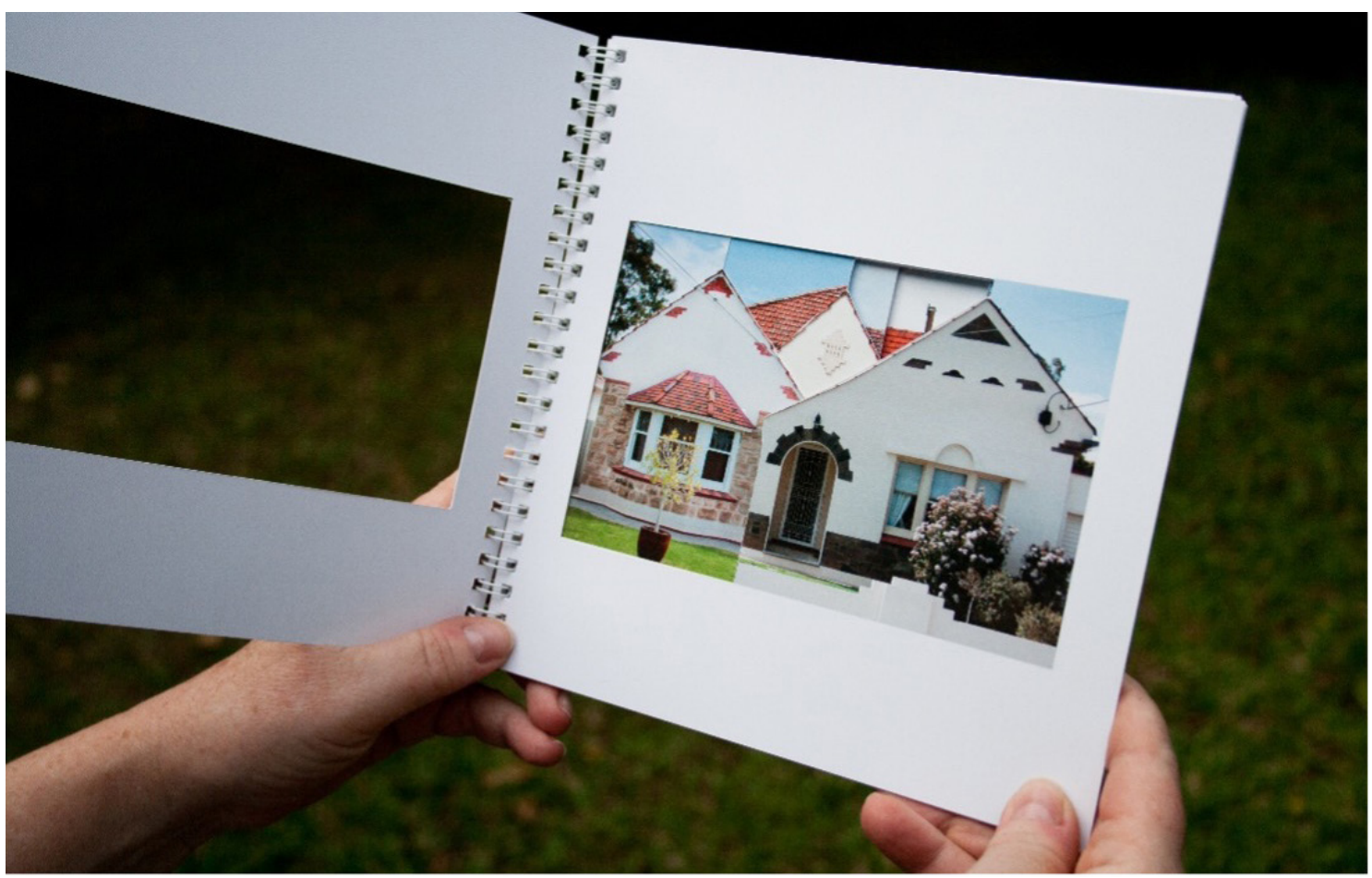

Figura 4. Manual Prático de Arquitetura, 2012. Segunda edição. Impressão digital, 20 x 20 × $1 \mathrm{~cm}$, edição de 30 exemplares. Fonte do autor. 
No caso destes trabalhos, a escolha pela tiragem pequena e pelo corte manual - para ambos fiz uma primeira versão como edição por demanda e depois estabeleci uma tiragem de 30 exemplares, lançada em 2012 durante a Feira Tijuana - não tinha nenhuma intenção de me adequar a lógica colecionista do mercado de arte para criar aqueles objetos "preciosos" que, assim como Lucy Lippard e sua turma na época da criação da Printed Matter, preferia escapar. Pelo contrário. Meu esforço era produzir da forma mais barata que conseguisse para tornar acessível a quem pudesse se interessar. 0 desafio nestes casos é que tiragens pequenas ou por demanda sempre acarretam valores individuais mais caros para o objeto final. Mas para poder fazer uma grande tiragem onde o valor de facas especiais para cada página se diluísse a ponto de ter um produto dentro de uma faixa de preço mais popular, o investimento inicial - e o trabalho envolvido posteriormente para distribuição e comercialização - tornaria sua produção proibitiva. A tiragem, portanto, estava muito mais ligada a questões pragmáticas entre a vontade de experimentação, custos, e possibilidades de produção, do que a regras de valorização que o mercado de arte tenta criar, muitas vezes de forma bastante artificial.

Outro livro que produzi e que surgiu exatamente desta mistura entre a vontade de experimentação através da página impressa e a vontade de poder compartilhar um projeto foi “拆 [chai]” (Figura 5). Nesta época, meados de 2016, eu vinha editando uma série de imagens que chamei de "Arqueologia da Vida Privada" e que tinha produzido durante uma residência artística em Xangai, na China. As imagens mostravam uma cidade que estava sendo demolida e reconstruída numa velocidade vertiginosa, o que criava ruínas instantâneas a céu aberto, deixando traços da vida privada das antigas moradias agora expostos em meio a escombros. Pela própria natureza do trabalho, pelo discurso, pelo assunto, eu tinha dúvidas se o melhor lugar para mostrar as imagens era a parede de uma galeria. Comecei então a trabalhar com a ideia de um livro, ainda sem muita certeza da escolha. Quando comecei a fazer orçamentos para estudar a viabilidade, me dei conta que se fizesse uma pequena tiragem de 200 exemplares, nos moldes que estava imaginando, o custo não seria muito maior que o de produzir 2 ou 3 impressões de grande formato, em papel algodão, emolduradas nos padrões museográficos, que muitas vezes acabam por anos escondidas na reserva técnica de alguma galeria até de fato serem compradas ou participarem de alguma exposição. E mais, neste trabalho, o discurso se constituía muito mais no sequenciamento das imagens do que numa ou outra imagem isolada, era importante ter uma visão geral do todo para um entendimento mais completo da obra. Com estes 200 exemplares, eu poderia experimentar melhor o trabalho, apresentar uma versão mais completa dele e, muito provavelmente, teria o retorno do investimento em um tempo relativamente curto, o que de fato aconteceu. Este circuito de feiras independentes e as facilidades de vender pela internet tornam estas pequenas tiragens bastante autossustentáveis em termos de custos, quando bem planejadas e principalmente para artistas que fazem do livro um meio frequente produção. Afinal, cada novo livro vai alavancando as vendas dos que já foram produzidos antes, ajudando a escoar estoques e reavivando as antigas produções. No fim, este livro foi um trabalho rápido, uma gravação ao vivo como diria Alec Soth, ainda que feito em offset, mas um processo importante para conseguir dar um fechamento para o projeto e colocá-lo em circulação. 


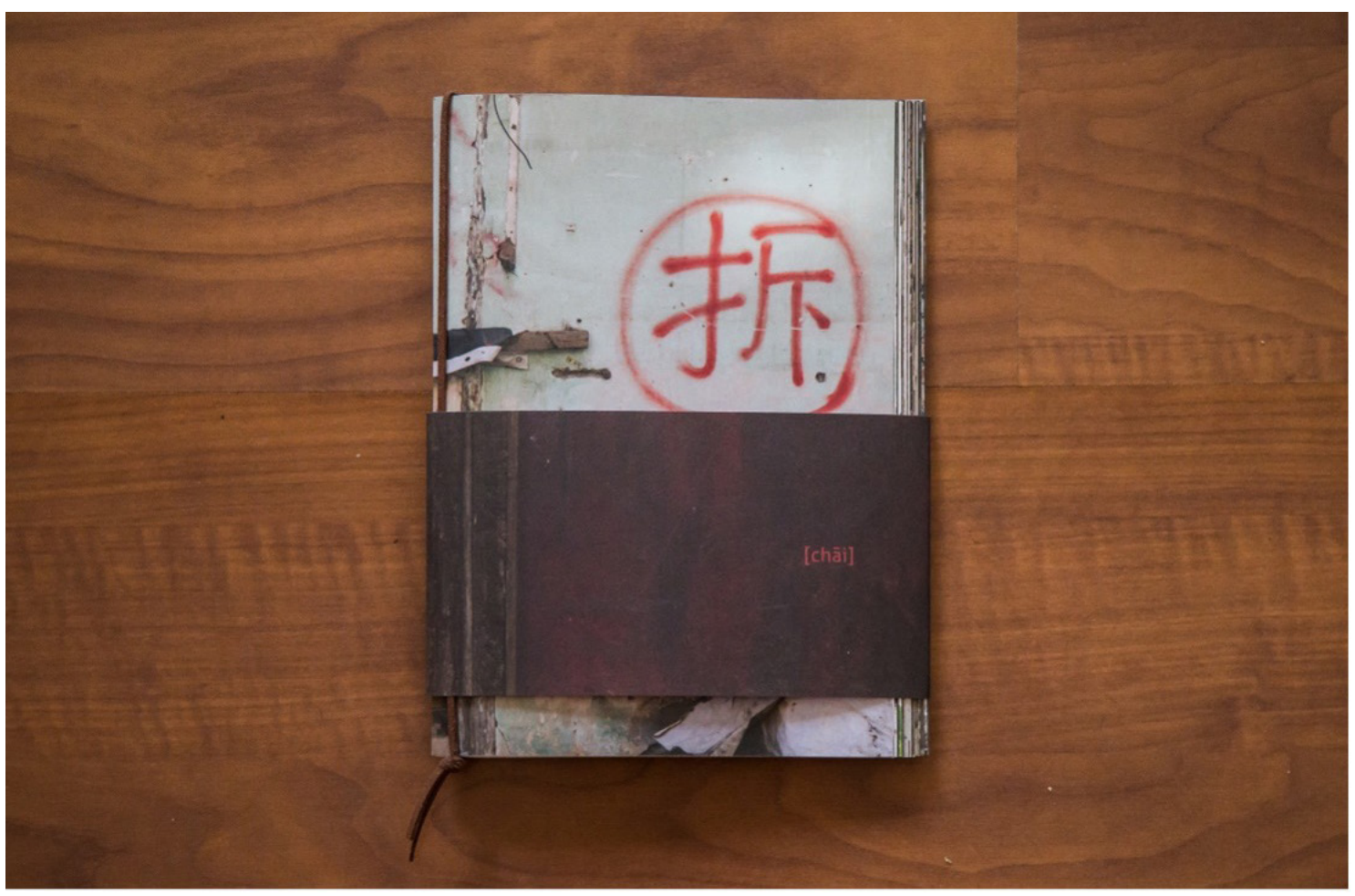

Figura 5. 拆 [chai], 2016. Impressão offset, 15 × 21 × 1 cm, edição de 200 exemplares. Fonte do autor.

\section{Um outro espaço de exposição}

Quando terminei de montar a exposição do projeto “Conhecidos de Vista”, em 2013, depois de muita dor de cabeça pelas tortuosas negociações com o espaço expositivo e as incertezas sobre a disponibilidade dos equipamentos prometidos, lembro de olhar o resultado final e me perguntar: Por que exposição? Por que não tinha escolhido o livro como formato para aquele projeto? Aquele processo todo tinha sido tão desgastante, tinha dado tanto trabalho e, em pouco mais de um mês, tudo que restaria seria apenas o registro do que passou.

Mas nem tudo é tão simples assim. Se certos projetos ganham ao adotar o livro como suporte, especialmente quando a experimentação através da página imprensa é importante ou quando o próprio conceito pede por este formato, quando a obra parte de uma instalação, sendo a relação do corpo do espectador com a escala importante, ou quando outros sentidos são convocados com mídias diversas, transformar o trabalho em livro pode se mostrar um grande desafio. 0 que naquele momento parecia a solução mais lógica e coerente para o projeto, logo se mostrou um caminho tão tortuoso quanto o que eu havia percorrido até ali.

Quando comecei a fazer o trabalho, não tinha bem certeza do formato que ele teria. Fui produzindo material e deixando esta decisão para o final, esperando que o próprio processo me indicasse o caminho. "Conhecidos de Vista" foi um projeto que desenvolvi a partir da visita de mais de 50 apartamentos, em Porto Alegre, onde a vista da janela da fachada era completamente barrada pelo prédio da frente. Neste processo, logo no início, passei a incorporar, através de 
gravações, os relatos que as pessoas faziam sobre os hábitos de algum vizinho que percebiam no seu dia a dia. Na maioria das vezes, não se conheciam pessoalmente. Foi daí que veio o nome: "Conhecidos de Vista".

A voz do morador, narrando estas pequenas histórias, passou a ser tão importante que acabei optando pelo formato audiovisual para apresentar o projeto. Montado pela primeira vez em 2013, na casa de Cultura Mario Quintana, em Porto Alegre, o trabalho consistia numa instalação que projetava a imagem dos interiores e das fachadas na parede, quase numa escala real e, através de uma caixa de som, as histórias narradas, nas vozes dos moradores, marcavam o tempo de transição entre as imagens. Jamais aparecia um rosto sequer. As vozes, e os móveis dos interiores, eram o gatilho para que o espectador pudesse criar, ele mesmo, a imagem mental de quem seria a pessoa que morava em cada apartamento.

Quando transpomos um trabalho para um livro, é parte do processo de design tentar traduzir os conceitos do projeto através de recursos gráficos, acabamentos, diagramação. Mas isto é muito diferente do primeiro exemplo que citei aqui, da "Escala de Cor das Coisas", onde o formato é dado pelo próprio conceito do projeto. Esta espécie de tradução que o design tanta criar é muito mais subjetiva, sutil, e pode apontar para caminhos bastante diversos.

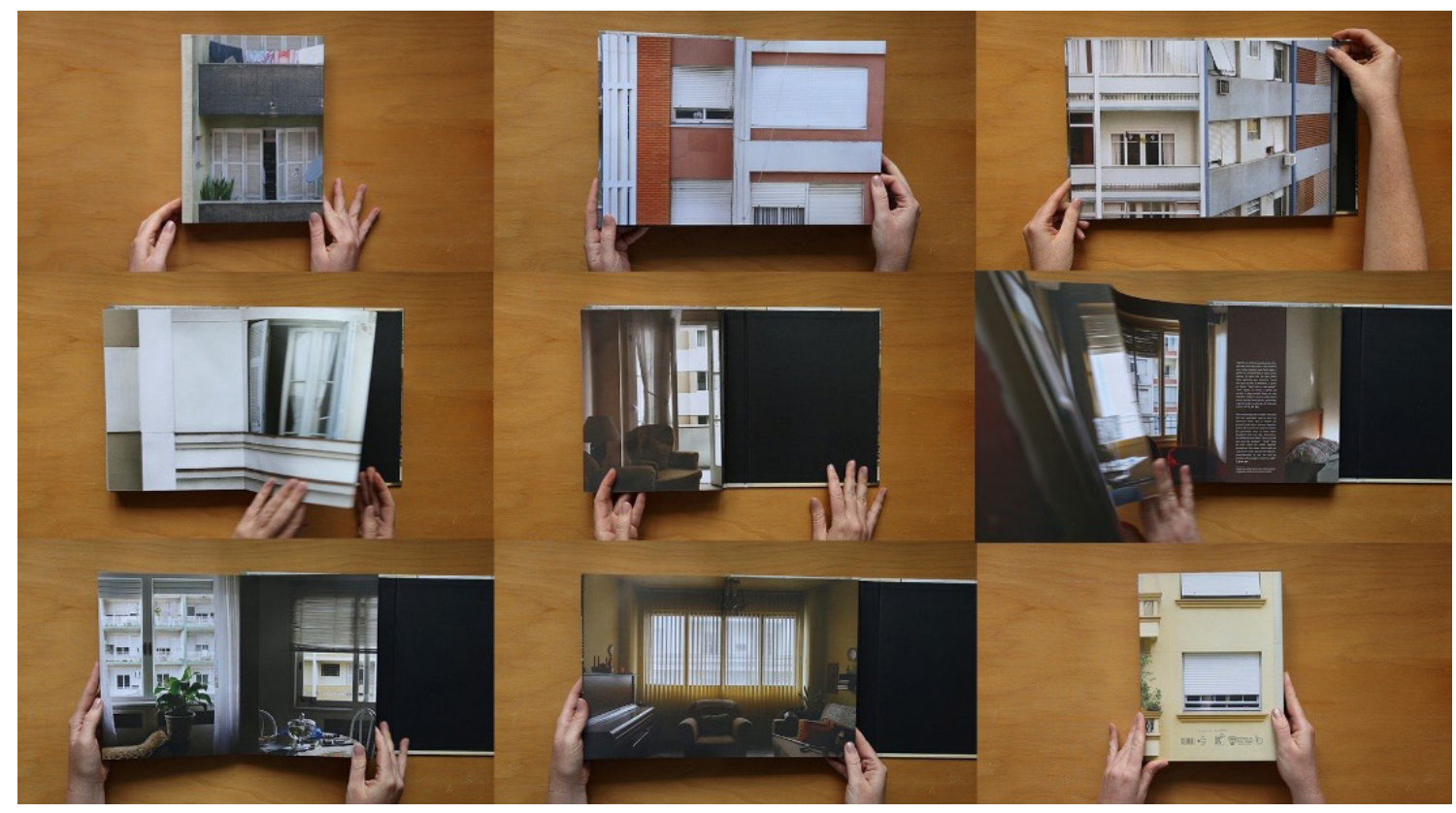

Figura 6. Conhecidos de Vista. 2018. Impressão offset, $18 \times 24 \times 3$ cm, edição de 1000 exemplares. Editora Incompleta. Fonte do autor.

No caso do "Conhecidos de Vista" (Figura 6 e 7), para me ajudaram a nortear as decisões que precisava tomar no projeto gráfico, fui estabelecendo uma série de conceitos e regras. Foram muitos bonecos de livro até chegar no resultado final. Primeiro, eu queria que o livro tivesse dois lados, que o papel fizesse as vezes de parede, que tivesse um dentro e um fora. Queria que o lado 
de dentro estivesse fechado de alguma forma, que ele não fosse visível num primeiro folhear, que ele precisasse ser descoberto. Mas o grande desafio era a questão das vozes. Como amenizar a falta que elas faziam? A voz traz uma presença tão forte que a simples transcrição do texto não dava conta de suprir. Adotar mídias externas, como um CD que acompanhasse o livro, ou colocar os áudios em um site, eram recursos que eu queria evitar. Queria que o livro se resolvesse nele mesmo, que não fosse dependente de outros aparelhos. A solução que encontrei acabou indo para um lado totalmente diferente do que eu podia imaginar quando comecei o processo. Para amenizar a perda de informação que a eliminação do áudio acarretava, optei por, desta vez, mostrar alguns dos rostos dos moradores, recurso que tinha evitado até então. Na parte de fora do livro, na parte das fachadas, é possível ver pessoas nas janelas nas situações mais corriqueiras. Assim, mantive os interiores anônimos, com os textos apenas transcritos, mas pude criar uma relação imaginada com estes rostos que agora apareciam do lado de fora. Também se criou uma espécie de leitura circular, pois é preciso passar pelo livro várias vezes para ir criando associações entre as pessoas que aparecem do lado de fora e os depoimentos e decorações que aparecem do lado de dentro. No fim, a edição do livro impresso e do trabalho como instalação audiovisual é completamente diferente, mas seguem sendo versões de um mesmo trabalho.

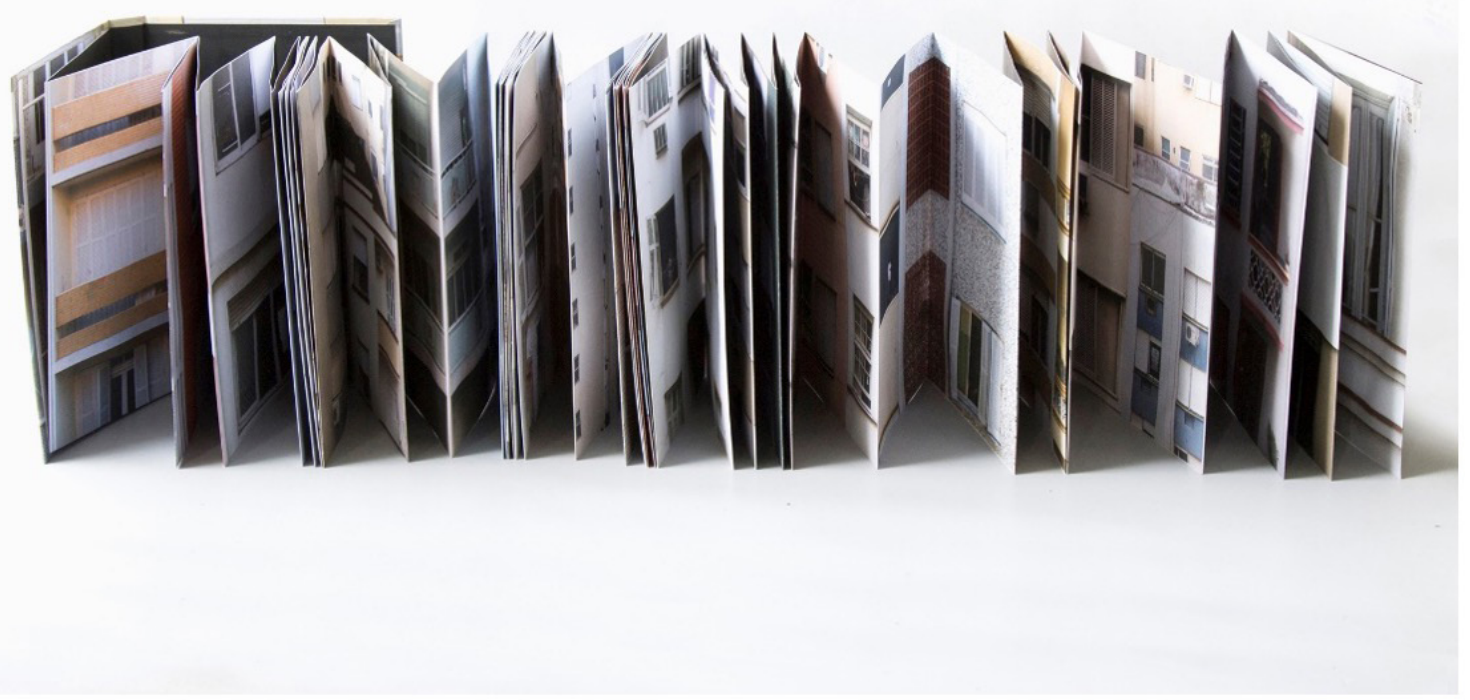

Figura 7. Conhecidos de Vista. 2018. Impressão offset, 18 × 24 × 3 cm, edição de 1000 exemplares. Editora Incompleta. Fonte do autor. 
Resolvidas todas as questões formais, o desafio agora era conseguir produzir. Se uma das razões para adotar o formato livro é tornar a arte acessível e democrática ao maior número de pessoas, contraditoriamente, o custo de produção pode torna-se tão alto que ele passa a ser quase proibitivo para a maioria dos artistas, ou pelo menos para que artistas embarquem nesta empreitada sozinhos. Nem todo projeto cabe na espontaneidade e no experimentalismo dos livros de baixa tiragem. Há projetos que necessitam de fato de um volume maior páginas, de imagens bem impressas, papéis especiais e uma tiragem considerável para viabilizar a produção de certos processos ou acabamentos gráficos. Se no exemplo anterior cheguei à conclusão que fazer o livro acarretaria o mesmo custo que produzir 2 ou 3 obras individualmente, neste caso o custo do livro era muito maior que a exposição inteira. "Conhecidos de Vista" era o típico projeto que se torna praticamente inviável sem leis de incentivo ou patrocínios institucionais.

A solução foi, mais uma vez, recorrer a editais de produção e buscar a parceria com uma editora, a Incompleta. Quando uma tiragem considerável é necessária para viabilizar um projeto, é fundamental pensar também como vai se dar a distribuição e a comercialização do trabalho depois. Nestes casos, trabalhar com uma editora pode ser providencial. A editora pode também ser importante para suprir uma série de outros papéis que são necessários na produção de livros mais complexos e que nem sempre o artista dá conta sozinho - embora eu, pessoalmente, goste de abraçar, como a figura do editor, do designer, do produtor gráfico, etc.

E por mais que me incomode um pouco esta dependência de subsídios e equipes que livros maiores tendem a necessitar, é interessante pensar que muitas obras de outras naturezas também só acontecem assim, vide grandes instalações e esculturas, projetos de intervenção urbana, etc. A questão é que o livro, por sua natureza, poderia ter mais autonomia na medida que se estabelecesse um mercado mais sólido e aquecido, onde as tiragens não demorassem tanto para encontrar seu fim. Quem sabe um dia? Por hora, seguimos tentando abrir caminhos com os meios que temos.

\section{Um formato com múltiplos fins}

Há um grande número de entusiastas, especialmente no meio fotográfico, que defendem que livro é a forma ideal para apresentar um projeto. Mesmo sendo eu mesma uma entusiasta dos livros, não acho que seja sempre assim. Há trabalhos que pedem livro, há trabalhos que pedem outros tipos de espaços e interações. Embora goste bastante do resultado final, acho que o "Conhecidos de Vista" é um exemplo bem didático do quanto pode haver perdas e ganhos quando transpomos certos projetos para a página impressa, o que não deixa de ser um exercício rico e estimulante. 0 livro pode ser tanto o formato principal de um projeto, quanto um formato secundário e complementar, trazendo até outros conceitos e leituras possíveis.

Enfim, seja para atender conceitos do próprio trabalho, para manter vivo o processo criativo ou para garantir uma maior circulação e permanência de projetos de fôlego, os livros sempre terão múltiplas utilidades e funções. E dentre todas elas, sigo fazendo coro às respostas dadas à revista Art-Rite, lá nos anos 70: democratizar o acesso, furando a bolha de um mercado excessivamente elitista e centralizador, é das coisas mais motivadoras para seguir levando adiante este grande desafio que é produzir livros, espacialmente no Brasil. 


\section{Referências}

ROBINSON, Walter e DEAK, Edit (org.) Art-rite Magazine no. 14. Nova York, 1976.

AUNT, Julie. Interview with Lucy R. Lippard, Printed Matter website. December, 2006. Disponível em: https://www.printedmatter.org/catalog/tables/41. Acesso em: 19 set. 2020.

KIM, Erik. 14 Lessons Alec Soth Has Taught Me About Street Photography. Disponível em: https://erickimphotography.com/blog/2014/02/25/14-lessons-alec-soth-has-taught-meabout-street-photography/

WHITE, Tony. From Democratic Multiple to Artist Publishing: The (R)Evolutionary Artist's Book. Art Documentation: Journal of the Art Libraries Society of North America, vol. 31, no. 1, 2012, pp. 45-56. Fonte: disponível em: www.jstor.org/stable/10.1086/664913. Acesso: 19 set. 2020. 


\section{Sobre a autora}

Com formação em Artes Visuais (UFRGS), Design (ULBRA) e mestrado em Poéticas Visuais (PPGAVUFRGS), Letícia Lampert vem desenvolvendo sua produção principalmente através da fotografia. Teve seu trabalho destacado em salões e prêmios tais como o Prêmio Pierre Verger de Fotografia (2013), o III Prêmio Itamaraty de Arte Contemporânea (2013), o Prêmio de Fotografia Chico Albuquerque (2019), entre outros. Em 2018, participou da Bienal do Mercosul, em Porto Alegre, da Bienal de Fotografia de Beijing, na China, e foi finalista do Prêmio Fola, em Buenos Aires - Argentina. Participou de residências artísticas no Brasil e no exterior tais como The Swatch Art Peace Hotel (2015), em Xangai - China, Residência FAAP (2017), em São Paulo e Pier 2 (2018), em Kaohsiung - Taiwan. Publicou até o momento 3 livros: Escala de Cor das Coisas (2009), Chai (2016) e Conhecidos de Vista (2018).

Lattes: http://lattes.cnpq.br/1333500017348130

Orcid: https://orcid.org/0000-0001-9552-6344

Recebido em: 30-10-2020 / Aprovado em: 16-11-2020

\section{Como Citar}

LAMPERT, Letícia (2020) Afinal, livro por quê? Revista Estado da Arte, Uberlândia. v.1, n.2, p.75-89, jul./dez. 2020. https://doi.org/10.14393/EdA-v1-n2- 2020-57999 